\title{
Review Artic:
}

\section{Microskills in Teaching in the Lecture Room of Medical Students}

\author{
M H Haidary', Asgar Hossain ${ }^{2}$, Md. Iqbal Bari ${ }^{3}$
}

\begin{abstract}
Teaching is a highly complex process. The medical teaching is more complex and difficult. There are certain basic skills of teaching e.g. the way the teacher presents lecture, use various teaching media, use of basic questionnaire and motivation etc. Besides these basic skills there are certain microskills of teaching. These are explaining, introductory procedure, closures and advanced questioning. Out of these microskills, explaining is the most important and powerful skill. Explaining has some components; e.g. clarity, fluency of language, use of ilfustration, variation of voice manners, structuring statements and finaily obtaining feedback. Every medical teacher should use these microskills in the lecture room for eflective teaching.
\end{abstract}

TAJ 2001; 14(2): 96-98

\section{Introduction}

Medical teaching is highly complex and difficult. Because medical teachers are to present something to medical students in very precise way which help them to treat disease in their real life of medical profession. For the beginners it needs to be broken down into meaningful and acquirable parts. ${ }^{1}$ There are certain skills for act of teaching which seems basic to effective teaching. These are the way, the teacher presents lecture, use various teaching media, use of basic questionnaires and motivation of the students learning. These skills represent an analysis of the student teaching process into relatively desecrate, well defined behaviours transferable to most classroom teaching context even be adapted purposefully in different combinations. Besides the basic skills of teaching, there are certain skills that are microskills in the sense that those are more sophisticated and the students are motivated for learning in the classroom if they are used in proper way. These are called microskills of teaching. There are several microskills of teaching that needs discussion for the benefits of our young medical teachers. The purpose of this article is to highlight of one of these microskills that is explaining which will help medical teachers to deliver lecture in a classroom setting very efficiently.

Histcry of microskills: After a long search for a single overall criteria of effective teaching, in the early 1960 s a number of educationists in the United States began to Jook for an alternative approach. The answer was to take the same path that the more nature science had already followed, if variables at one level of phenomenon do not exhibit lawfulness, break them.

A search was commenced for the so called, microcriteria of teacher effectiveness, the

\footnotetext{
'A5sociate Prolesson, Depanment Ol Paediairics, Rajshabi Medical College, Rajshahi-6000, Bangladesh

2 Associate Prolessor. Depariment Of Paediatnes, Ra,shahi Medical College, Ra, shahi-6000, Bangladesh.

${ }^{4}$ Consufant, Department Ot Paediatrics, Rajthahi Mecical Collega, Rajshahi-6000, Bangladesh.
} 
effectiveness of small specifically defined aspects of the teacher's act. ${ }^{2,3}$ This new line of endeavors coalesce with the concept of microteaching which was then being developed. The act of teaching might be regarded as a cycle comprising three broad phases: (i) a pre-active phase, (ii) an interactive phase, (iii) a post active phase.

(i) In the pre-active phase, the teacher is mainly concerned with planning, Considering the objectives of the students, the teacher selects and organizes contents and strategies and determines skills. (ii) The interactive phase involves the teachers in a variety of patterns of most interchange with students as the objectives of the teaching are pursued. (iii) In the post active phase, the teacher evaluates often with students the teaching in terms of achievement of objectives and performances of individuals. Now goals and plans are foreshadowed, the needs of students diagnosed and follow up work determined. These three phases obviously interlock and overlap. The teacher should use different microskills in three phases and make the act of teaching successful. These microskills are as follows: i) Explaining ii) Introductory procedure and closure and iii) Advanced questioning. In the present article we like to highlight, explaining because this is most powerful mieroskills in teaching.

The skill of explaining: There are numerous definitions of explaining. But there is one interesting common factor in definitions advanced by several educational theorists. The need fot explanation arises when a person evaluates something, which according to his experience was not to be expected, or which he can not relate to his experience. It is the function of the explanation io fill the gaps between the person's experience and this new phenomenon. Explanation imparts knowledge in such a way that interdependence between events is made explicit. The job of the explanation is to explain something to some one, is to fill in the gap between his audience's knowledge or beliefs about some phenomenon and what he toke to be actual stale of affairs and anderstanding seems to involve seeing connections. This common factor is of course, the idea referred to by the phrases, "to fill the gap between, interdependence between" and seeing connections. To explain is to make links. Explaining is one way the teacher tells students something. In telling, the teacher organize lesson contents 50 that the student is exposed to the contents in a planned and controlled sequences. ${ }^{5}$

Types of explanation: Research in the past twenty years has enabled the development of a set of explanation types useful for classroom teachers in wide range of subjects, $A$ brief consideration of these types will indicate theoretical rationale for the selection of appropriate generalization. ${ }^{7}$

Type I explanation or generalization: If emphasizes generalization such as scientific laws. judgment based on reasonable statistical probabilities and established rules or norms, ${ }^{\text {B }}$

Type II explanation or functional explanation: Type II explanation or functional explanation utilize generalization which states a purpose, intention or desire that seems inherent in a person or in the design of a object.

Type III explanation: This type of explanation usually occurs in a scale of time and space larger than that of other types of explanation. A series of events or steps is constructed which resembles in the situation to be explained.

As a basis of panning and presenting explanations in the classroom, teachers used to be alert of these different types of explanations. The skill of explaining is basic to the teaching of most topics in all curriculum areas. A teacher explains to provide an answer to a why, what and how questions in such a way that understanding becomes clearly evident. Skillful explaining depends on specific techniques of the presentation by the teacher. The techniques are clarity and fluency in language, use of illustrations, variations of voice and manners, structuring statements and finally obtaining feed back.

\section{Conclusion}

In medical science, students are taught problem-solving things, which they will utilize, in their practical life in real world. Therefore, every 
teaching aspect is important for them. The teacher in the lecture room may present a very important matter of human life. So the lecture must be effective. The students will learn something that will help them to understand the subject in their clinical settings. Therefore, medical teachers must use various microskills especially explaining during presentation of lecture in the lecture room.

\section{References}

1. Sydney T C. Micro Skills: Retrospect and Prospect. Report to the Education Research and Development Committee, University of Sydney. $1980,83-9$.

2. Gage N L. An Analytical Approach to Research on Instructional Methods. Phi Delta Kappon $1968 ; 49(10): 601-6$.
3. Gage N L. Paradigms for Research on Teaching. In: Handbook of Research on Teaching. Chicago 1962; 94-141.

4. Smith BO, Meux MO ef al. A study of Logic of Teaching, University of Illinois Press, Urbana $1970 ; 123$.

5. Hog $A C$, Foster $\cup K$. Understanding Teaching Procedures. Australia, Melboume 1973; 52.

6. Martin $\cup$ R. Explaining, Understanding and Teaching. McGraw-Hill, New York, 1970; 45.

7. Brown G, Hatton N. Explanations and Explaining D.E.S. Teacher Education Project, Macmillan Education, Basingstoke, 1982; 23-35.

8. Swift L. F. Explanation in Language and Concepts in Education. Chicago, 1961; 56-8.

9. Nuthal G A, Lawrence P J. Thinking in the class room. New Zealand Council for Educational Research, Wellington, 1965; 36-9.

All correspondence to: Dr. MH Haidary Associate Protessor Department Of Paedlatrics Rajshahi Medical College Rajshahi-6000, Bangladesh. 